\title{
Applying a ten-step framework as a strategy for implementing a guideline on emotional support for preschool-aged children in day-surgery nursing
}

\author{
Hanna-Leena Melender*1, Salla Pirkola ${ }^{1}$, Kaisa Imppola ${ }^{1}$, Helinä Ahonen ${ }^{2}$, Saija Seppelin ${ }^{2}$ \\ ${ }^{1}$ Department of Social and Health Care, VAMK University of Applied Sciences, Vaasa, Finland \\ ${ }^{2}$ Vaasa Central Hospital, Vaasa, Finland
}

Received: May 18, 2021

DOI: $10.5430 /$ jnep.v11n10p49
Accepted: June 16, 2021

Online Published: June 20, 2021

URL: https://doi.org/10.5430/jnep.v11n10p49

\begin{abstract}
The purpose of this clinical practice guideline implementation effort was to put into practice a Finnish nursing guideline on emotional support for preschool-aged children in day-surgery nursing for nurses at a day-surgery unit. The strategy was to use a 10-step framework in the implementation process. In this brief article, the strategy and the outcomes of the guideline implementation effort are described.
\end{abstract}

Key Words: Clinical practice guideline, Day-surgery nursing, Emotional support, Evidence-based practice, Implementation, Preschool-aged children

\section{INTRODUCTION}

Implementing an evidence-based practice (EPB) change is one of the key points in the seven-step Evidence-Based Practice process. ${ }^{[1,2]}$ Fixen (2005, pp. 5) described implementation as "a specific set of activities designed to put an activity or programme of a known dimension into practice". ${ }^{[3]}$ The process of implementation of scientific evidence is associated with the goal of improving population health. When evidence-based interventions are implemented in community and clinical settings, it is also important to evaluate the outcomes of the implementation process. ${ }^{[4]}$

The use of clinical practice guidelines to promote evidencebased decision-making is recommended by the Institute of Medicine. ${ }^{[5]}$ Putting clinical practice guidelines into practice is associated with three concepts: diffusion, dissemi- nation and implementation. Diffusion is a passive concept and means, for example, the publishing of the guideline. In dissemination, information is actively tailored and focused, based on the properties of the target group and communicated through different channels. Implementation is even more active and includes support activities for the transformation of the knowledge included in the guideline into clinical practice. ${ }^{[6,7]}$ Use of research evidence in nursing practice is not always self-evident, and Severinsson (2012, pp. 142), for example, asked in her editorial: "Is implementation the missing link?". ${ }^{[8]}$ In Finland, in a national survey published in 2018, $67 \%$ of responding nurses and $57 \%$ of responding nursing leaders and experts stated that information about evidencebased practice models is not always disseminated in service organizations. Of the responding nursing leaders and experts, only $52 \%$ stated that practicing nurses are supported to use

\footnotetext{
*Correspondence: Hanna-Leena Melender; Email: hanna-leena.melender@outlook.com; Address: VAMK University of Applied Sciences, Wolffintie 27-31, 65200 Vaasa, Finland.
} 
summarized evidence in their work. ${ }^{[9]}$

Nurses have positive attitudes toward the use of guidelines, albeit the guidelines are not always constantly used. ${ }^{[10]}$ To support guideline implementation, Lineker and Husted ${ }^{[11]}$ have recommended the use of a theoretical framework. Overall, the use of frameworks, models or other systematic approaches are recommended for the implementation of scientific evidence. ${ }^{[2,4]}$ In this guideline implementation effort, the strategy was to use Metz's ${ }^{[12]} 10$-step framework in the implementation process. The impetus for choosing the framework was due to it being based on lessons learned from earlier research findings and because it offers concrete steps on how to proceed.

The purpose of this clinical practice guideline implementation effort was to put into practice a Finnish nursing guideline on emotional support for preschool-aged children in day-surgery nursing ${ }^{[13]}$ for nurses at a day-surgery unit. The unit is located in a small central hospital in Finland, treating 500-600 pediatric surgery patients per year.

\section{DESCRIPTION OF THE STRATEGY AND OUTCOMES}

The strategy and outcomes of the clinical practice guideline implementation effort are described according to the ten steps presented by Metz. ${ }^{[12]}$

In Step 1, the need for change was identified ${ }^{[12]}$ by the head nurse of the day-surgery unit at the beginning of Year 2018 . At this phase, the current gap in practice should be identified. ${ }^{[12]}$ The guideline on emotional support for preschoolaged children in day-surgery nursing ${ }^{[13]}$ was not yet in regular use at the unit, and this was identified as a gap in practice. For the guideline implementation effort, a following research question was formulated: What are the outcomes of the guideline implementation effort to put into practice a nursing guideline on emotional support for preschool-aged children in day-surgery nursing for nurses at a day-surgery unit, when applying a ten-step framework as a strategy? The quality ${ }^{[14]}$ of the guideline was appraised as good. An organizational permission (22.2.2018/\$1/ylihoitaja OPER) to conduct the guideline implementation effort with surveys among nursing staff was obtained.

Step 2 comprised an assessment by questionnaire of the nurses' abilities to adopt evidence-based practice. ${ }^{[12]}$ The survey revealed that most of the responding nursing staff members did not know about the existence of the guideline, and that the guideline was quite rarely utilized. Moreover, the staff reported challenges in providing emotional support for preschool-aged children. These issues implied that there was a need for change. Attitudes toward the use of guidelines in day-surgery nursing were positive. This implied a good starting point for the guideline implementation effort since it was concluded that the staff had a good attitudinal basis to adopt new evidence-based knowledge and that there was a need for that knowledge (see the Results section).

In Step 3, the support of stakeholders was acquired. ${ }^{[12]}$ The central stakeholder was the Director of Nursing of Acute Care Services, who supported and monitored the process. Notification of the guideline being a "good fit" for the unit (Step 4) ${ }^{[12]}$ was made. The guideline matched the needs of the target patient group and the recommendations (see Table 1) could be taken as part of the unit's actions and put into use by trained frontline staff.

Table 1. The recommended practices included in the guideline $^{[13]}$

- supporting the parents to participate in the day-surgical care

- ensuring that the child is well prepared by a preoperative phone call

- helping the child with issues causing anxiety during day-surgery care (the specific methods are related to the presence of the parents at different phases of the day-surgery procedure, the presence of hospital entertainers, watching a pleasant video, discussions with the same staff member at different phases of the day-surgery procedure, and a combination of getting acquainted with the perioperative unit, watching a video presenting incidents during perioperative care and participating in a program planned by a kindergarten teacher, including, for example role play games)

- relieving anxiety in parents during day-surgery care

- completing the guidance of the family by a postoperative call

Step 5 dealt with any decision to make necessary adaptations. ${ }^{[12]}$ The team considered the guideline carefully to ensure that its five recommended practices met the needs of the local setting, without sacrificing the core elements required to produce expected outcomes. After this consideration, the team decided that no adaptations were needed.

Step 6 comprises seeking information, technical assistance, and program consultation. ${ }^{[12]}$ Research evidence on the implementation of guidelines was searched for in Medic (a Finnish database) as well as PubMed and Cinahl databases. No technical assistance or program consultation were needed. However, specialist assistance was sought from the clinical nurse specialist of the hospital who assisted in preparing a manual for the staff on the documentation of emotional support for children in the electronic patient record according to the Finnish Care Classification system.

The staff was trained ${ }^{[12]}$ in Step 7, in September 2018. The training session was planned and conducted based on the 
findings of a systematic review on educational interventions and other strategies for guideline implementation. ${ }^{[15]}$ This systematic review had found that when educational interventions had been conducted for guideline implementation, varying learning/teaching methods and several contents in educational interventions had resulted in positive effects. Based on this evidence, a 90-minute training session was conducted. During a short lecture, the contents of the guideline and the results of the survey conducted in Step 2 were presented. After that, the participants were divided into groups to discuss what parts of the guideline were already in use and to produce ideas on how to implement the guideline into use in its entirety. Finally, in a common discussion, all participants discussed the details of the guideline implementation and made a plan on how to proceed (see Table 2). Copies of the guideline were used as a learning material. The number of participating nurses was 36 (the number of permanent nursing staff was 38 ).

Table 2. The plan for the new procedures to support guideline implementation

- The use of the guideline will be the topic of a staff meeting once or twice a year to keep it of current interest.

- The guideline will be on display in the unit.

- The existing websites of the unit include a journey map of the day of a pediatric patient and will now be used in the emotional preparation of children and parents by adding the website link into the invitation letter for the day-surgical procedure.

- The outpatient clinic, which the child visits before the day-surgical procedure, will be sent the link of the websites mentioned above to assist staff to emotionally prepare children and parents for the procedure already there.
The initial implementation of the guideline ${ }^{[12]}$ began in Step 8 in September 2018, with a goal that all nurses in the unit would utilize the guideline by the end of May 2019. Procedures to support guideline implementation (see Table 2) were conducted. The websites were subsequently improved to also be accessible for persons with visual impairments.

In Step 9, the outcomes were evaluated ${ }^{[12]}$ with a questionnaire. The findings are presented in the Results section.

In Step 10, feedback loops and ongoing opportunities for learning and reflection were created. ${ }^{[12]}$ These are included in staff morning meetings. The responsibility for implementing them lies especially with the nurses responsible for pediatric day surgery nursing.

\section{Results}

Table 3 presents the results of the survey conducted in Steps 2 and 9. The results revealed that after the initial implementation had finished (the survey in Step 9), the guideline was more often familiar to the nursing staff members, and it was more often utilized. No challenges were reported in providing emotional support for preschool-aged children or in the use of the guideline. Attitudes toward the use of guidelines in day-surgery nursing were approximately as positive as they were in the beginning of the implementation process. Statistical significance of the differences was not examined, since it would not have been reasonable because of the small sample sizes.

In the survey conducted in Step 9, 80\% of respondents $(\mathrm{n}=$ 16) reported that they had participated in the training session conducted in Step 7.

Table 3. The results of the survey conducted in Steps 2 and 9

Step 2 (April 2018)
$\mathbf{n}=14$, response rate $37 \%$

$21 \%(n=3)$ knew about the guideline, and of those who knew about it, 100\% ( $\mathrm{n}=3)$ used it occasionally, but no one regularly.

Two out of five recommended practices published in the guideline were in use at least to some extent among those who had used it. $93 \%(n=13)$ stated that the implementation of guidelines in day-surgery nursing is very or somewhat important.

$79 \%(n=11)$ reported challenges in providing emotional support for preschool-aged children.

\section{Step 9 (October - November 2019)}

$\mathbf{n}=\mathbf{2 0}$, response rate $57 \%$

$80 \%(n=16)$ knew about the guideline, and of those who knew about it, $43.8 \%(n=7)$ used it occasionally and 50\% (n=8) regularly.

All five recommended practices published in the guideline were in use at least to some extent among those who had used it. $95 \%(n=19)$ stated that the implementation of guidelines in day-surgery nursing is very or somewhat important.

No challenges in providing emotional support for preschool-aged were reported.

No challenges in use of the guideline were reported.

\section{DISCUSSION}

Limitations of this guideline implementation effort are related to the low response rates and small sample sizes of the

Published by Sciedu Press surveys. Because of the latter issue, examination of statistical significance of the differences was not reasonable. However, the nature of this work was not to produce knowledge 
which could be generalized to a larger population, since this was a quality improvement task of one small unit. Another limitation is that the questionnaire used in the surveys was self-developed by the authors and not a validated instrument Nevertheless, it was not possible to find a suitable validated tool for the purposes of this kind of guideline implementation effort which focused on a specific clinical topic. The evaluation of the outcomes was conducted at the staff level ${ }^{[4]}$ and produced useful information on how the guideline implementation had succeeded from the point of view of the nurses' practice. A limitation is that no patient outcomes ${ }^{[4]}$ were evaluated, which remains as a challenge of future guideline implementation efforts. In the survey conducted in Step 9, $20 \%$ of the respondents had not participated in the training session conducted in Step 7. This hampers the possibility to draw direct conclusions on the effects of the training session.

The strength of this guideline implementation effort was related to the high participation among nursing staff in the training session. Nearly all the nursing staff of the unit participated and had an opportunity to participate in making the plan for the new procedures to support guideline implementation. Use of varying learning/teaching methods and several contents in the guideline implementation training ${ }^{[15]}$ offered opportunities for participants to actively produce ideas and discuss them with colleagues. These both may have improved the results. Moreover, a strength of this guideline implementation effort was that it was based on a systematic framework which guided the process. The framework presented by Metz ${ }^{[12]}$ was appropriate for the use of this guideline implementation and the use of it or some other framework, model or other systematic approach ${ }^{[2,4,11]}$ can be recommended to give directions for the implementation of guidelines.

After the initial implementation had finished, more nursing staff knew the guideline than at the beginning of the implementation process. It was used by more nurses, and more single recommended practices included in the guideline were in use. Attitudes toward guideline use were very positive already at the beginning of the implementation process, and they remained highly positive also after the initial implemen- tation had finished. No challenges in the guideline use were reported. This implies that the recommendations included in the guideline were relevant for the practice of nurses in the day-surgery unit. This is important for the quality perspective of the pediatric day-surgery nursing in the unit. When emotional support for preschool-aged children is addressed in an all-encompassing, evidence-based way, it supports the health of the children. Moreover, during this process, the nurses have had an opportunity for professional development regarding how to support preschool-aged children emotionally.

The work to support the use of the guideline is continuing. Interviews with the nurses especially responsible for pediatric day surgery nursing were planned to gather information about the reflections and learning needs of the staff regarding the guideline use. However, because of COVID-19, these interviews have now been postponed to a later phase. Moreover, a new survey among the staff will be conducted later to show any potential long-term effects.

In order to disseminate ${ }^{[16]}$ the results of this clinical practice guideline implementation effort, its process and outcomes have been presented in a local, in a national and in an international conference. Moreover, a short news bulletin on the topic has been posted on Facebook (https://www.facebook.com/VAMKofficial/ph otos/3135451376517618) and Instagram (https: //www . instagram.com/p/B-RNOZynuVC).

\section{CONClusion}

The results of this guideline implementation effort were promising. The use of a framework, model or some other systematic approach to provide directions for the implementation of guidelines is recommended. Moreover, an implementation training offering opportunities for participants to actively produce ideas and discuss them with colleagues to make a common practical plan regarding the procedures to support guideline implementation is recommended.

\section{CONFLiCtS OF INTEREST Disclosure}

The authors declare that there is no conflict of interest.

\section{REFERENCES}

[1] Melnyk BM, Gallagher-Ford L, Fineout-Overholt E, et al. The establishment of evidence-based practice competencies for practicing registered nurses and advanced practice nurses in real-world clinical settings: Proficiencies to improve healthcare quality, reliability, patient outcomes, and costs. Worldviews Evid Based Nurs. 2014; 11: 5-15. PMid:24447399 https://doi .org/10.1111/wvn. 12021
[2] Gallagher-Ford L. The evidence-based practice competencies related to implementation. In Implementing the evidence-based practice (EBP) competencies in healthcare: a practical guide to improving quality, safety and outcomes. Edited by Melnyk BM, Gallagher-Ford L, Fineout-Overholt E. Indianapolis, IN: Sigma Theta Tau International; 2017: 109-128.

[3] Fixsen DL, Naoom SF, Blasé KA, et al. Implementation Re- 
search: A Syntehesis of the Literature. University of South Florida. [Internet]. Tampa, FL: Louis de la Parte Florida Mental Health Institute, The National Implementation Research Network (FMHI Publication \#231), 2005. [cited 2021 June 9]. Available from: http://nirn.fpg. unc.edu/sites/nirn.fpg.unc. edu/files/resources/NIRN-MonographFull-01-2005.pdf

[4] Estabrooks PA, Brownson RC, Pronk NP. Dissemination and implementation science for public health professionals: an overview and call to action. Prev Chronic Dis. 2018; 15: 180525. PMid:30576272 https://doi.org/10.5888/pcd15.180525

[5] Institute of Medicine. Clinical Practice Guidelines We Can Trust. Washington, DC: The National Academic Press; 2011.

[6] Lomas J. Diffusion, dissemination, and implementation: who should do what? Ann N Y Acad Sci. 1993; 703: 226-237. PMid:8192299 https://doi.org/10.1111/j.1749-6632.1993.tb26351.x

[7] Sipilä R, Lommi ML. Hoitosuositukset eivät muutu hoitokäytännöiksi itsestään (Treatment recommendations do not automatically translate into treatment practices). Duodecim. 2014; 130: 832-839. (In Finnish, Summary in English)

[8] Severinsson E. Nursing research in theory and practice - is implementation the missing link? J. Nurs. Manag. 2012; 20: 141-143. PMid:22380408 https://doi.org/10.1111/j.1365-2834.20 $12.01387 . \mathrm{x}$

[9] Holopainen A, Siltanen H, Hahtela N, et al. Toteutuuko näyttöön perustuva toiminta Suomessa? Raportti nykytilasta hoitotyön edustajien kuvaamana. Research report. Hoitotyön tutkimussäätiö (Nursing Research Foundation) \& Sairaanhoitajaliitto (The Finnish Nurses Association); 2018. (In Finnish)

[10] Koota E, Kääriäinen M, Lääperi M, et al. Emergency nurses' Evidence-Based Practice attitudes, self-efficacy, knowledge, skills and behaviors before an educational intervention - Baseline of a randomized controlled trial. Collegian. 2020; 27: 361-369. https : //doi.org/10.1016/j.colegn.2019.11.002

[11] Lineker SC, Husted JA. Educational interventions for implementation of arthritis clinical practice guidelines in primary care: effects on health professional behavior. J. Rheumatol. 2010; 37: 1562-1569. PMid:20595274 https://doi.org/10.3899/jrheum. 100045

[12] Metz AJR. A 10-Step Guide to Adopting and Sustaining Evidence-Based Practices in Out-Of-School Time Programs. Brief Research-to Results. Child Trends. 2007; 16. https://www. childtrends.org/wp-content/uploads/2 007/04/child_trends-2007_06_04_rb_ebp2.pdf

[13] Hotus. Leikki-ikäisen lapsen emotionaalinen tuki päiväkirurgisessa hoitotyössä hoitosuositus (Emotional support for preschool-aged children in day-surgery nursing A nursing practice guideline). [Internet]. Hoitotyön Tutkimussäätiö (Nursing Research Foundation), 2016. [cited 2021 May 13]. Available from: https://www.hotus.fi/leikki-ikaisen-emotionaaline n-tuki-paivakirurgisessa-hoitotyossa-hoitosuositus

[14] Quaseem A, Forland F, Macbeth F, et al. Guidelines International Network: toward International Standards for Clinical Practice Guidelines. Ann. Intern. Med. 2012; 156: 525-531. PMid:22473437 https : //doi.org/10.7326/0003-4819-156-7-201204030-00009

[15] Häggman-Laitila A, Mattila LR, Melender HL. A systematic review of the outcomes of educational interventions relevant to nurses with simultaneous strategies for guideline implementation. J. Clin. Nurs. 2017; 26: 320-340. PMid:27240188 https://doi.org/10.1111/ jocn. 13405

[16] Melnyk BM. The evidence-based practice competencies related to disseminating evidence. In Implementing the evidence-based practice (EBP) competencies in healthcare: a practical guide to improving quality, safety and outcomes. Edited by Melnyk BM, Gallagher-Ford L, Fineout-Overholt E. Indianapolis, IN: Sigma Theta Tau International. 2017; 163-181. 